\title{
ENTRE KIERKEGAARD E HEIDEGGER: UMA REFLEXÃO SOBRE O SENTIDO DA ANGÚSTIA
}

\author{
Marcos André Webber ${ }^{1}$ \\ Universidade do Vale do Rio dos Sinos (UNISSNOS) \\ https://orcid.org/0000-0003-3024-9133 \\ E-mail: marcoswebber@wcacontabilidade.com.br \\ Suelen da Silva Webber ${ }^{2}$ \\ Faculdade da Serra Gaúcha (FSG) \\ (iD) https://orcid.org/0000-0002-3294-9726 \\ E-mail:suelenwebber@terra.com.br
}

\section{RESUMO:}

O presente trabalho tem como objetivo central indicar alguns pontos de aproximação e distinção entre o sentido atribuído por Kierkegaard à angústia na obra $O$ conceito de angústia, e o modo pelo qual Heidegger aborda tal conceito no âmbito da analítica existencial desenvolvida em Ser e tempo. Muito embora seja possível apontar inegáveis semelhanças no modo pelo qual os dois autores compreendem o fenômeno da angústia, algumas distinções podem ser feitas se analisados os contextos a partir dos quais os pensadores se ocuparam do tema em questão. Enquanto que para Kierkegaard a angústia é vista em estrita relação com o pecado, a fé e a liberdade, Heidegger busca atribuir ao fenômeno do angustiar-se um sentido ontológico, inscrito no projeto da ontologia fundamental, a partir do qual torna-se possível ao Dasein ser livre para escolher a si mesmo, e assim assumir o modo próprio de ser.

PALAVRAS-CHAVE: Angústia; Liberdade; Ontologia fundamental.

\section{BETWEEN KIERKEGAARD AND HEIDEGGER: A REFLECTION ON THE MEANING OF ANXIETY}

\begin{abstract}
:
This paper aims to suggest some points of convergence and distinction between the meaning that Kierkegaard assigns to anxiety in the oeuvre The concept of anxiety, and the way Heidegger addresses the same concept through the undertaking of existential analytic in Being and time. Although it may be possible to suggest undeniable similarities in the way both authors understand the phenomenon of anxiety, some distinctions may be set if well analyzed the context in which both thinkers addressed the subject. Whereas Kierkegaard understands anxiety related to sin, faith and freedom, Heidegger attributes to the phenomenon of anxiety an ontological meaning, inscribed in the project of a fundamental ontology, from which becomes possible for Dasein the freedom to choose itself, and thus assume the proper way of being.
\end{abstract}

KEYWORDS: Anxiety; Freedom; Fundamental ontology.

\footnotetext{
${ }^{1}$ Doutorando em Filosofia pela Universidade do Vale do Rio dos Sinos (UNISINOS), São Leopoldo - RS, Brasil - Brasil. Bolsista PROSUC/CAPES.

2 Doutora em Direito pela Universidade do Vale do Rio dos Sinos (UNISINOS), São Leopoldo - RS, Brasil. Professora da Faculdade da Serra Gaucha (FSG), Caxias do sul - RS, Brasil.
}

WEBBER, Marcos André; WEBBER, Suelen da Silva. Entre Kierkegaard e Heidegger: uma reflexão sobre o sentido da angústia. Griot : Revista de Filosofia, Amargosa - BA, v.18, n.2, p.100-113, dezembro, 2018. 100 


\section{Considerações Iniciais}

Søren Kierkegaard e Martin Heidegger são pensadores que, em diversos momentos da sua obra, ocuparam-se do tema da angústia. Embora os contextos nos quais o tema aparece em suas obras sejam distintos, é possível sustentar que existem algumas semelhanças no modo pelo qual os dois autores abordam o fenômeno da angústia. Nesta perspectiva, o presente trabalho tem como objetivo principal indicar alguns pontos de aproximação e distinção entre o sentido atribuído por Kierkegaard à angústia na obra $O$ conceito de angústia, e o modo pelo qual Heidegger aborda tal conceito no âmbito da analítica existencial desenvolvida em Ser e tempo. Almeja-se poder evidenciar que nos dois casos a angústia possui uma função essencial, tanto na dialética existencial de Kierkegaard quanto na elaboração do projeto da ontologia fundamental heideggeriana.

Para uma adequada abordagem do tema aqui proposto, precisamos inicialmente levar em conta que Kierkegaard publicou $O$ conceito de angústia em 1844, sob o pseudônimo de Vigilius Haufniensis, enquanto que Ser e tempo foi publicado por Heidegger apenas em 1927. E mais do que isso, devemos levar em consideração que Heidegger não lia dinamarquês, idioma original dos escritos de Kierkegaard, o que significa que a leitura feita por Heidegger dos textos do autor dinamarquês se deu através de traduções para a língua alemã. Conforme nos mostra Thonhauser em textos recentes, o mais provável é que o acesso de Heidegger aos escritos de Kierkegaard tenha ocorrido via Karl Jaspers, provavelmente no inverno de 1919-20, quando Heidegger estudou cuidadosamente a obra Psychologie der Weltanschauungen, publicada por Jaspers em 1919, e sobre a qual viria a escrever uma resenha crítica no início de 1920 (THONHAUSER, 2016, p. 294).

Desse modo, podemos afirmar que, ao tratar do tema da angústia em Ser e tempo, Heidegger já havia tido contato com $O$ conceito de angústia. Três notas de rodapé ( $\S 44,45$ e 68$)$ incluídas pelo próprio autor deixam isso muito claro, visto que o filósofo alemão posiciona-se diante dos escritos do escritor religioso dinamarquês. Disso não decorre, contudo, que Heidegger tenha simplesmente repetido Kierkegaard. Apesar das referências que encontramos nos textos, algumas delas trazendo certo tipo de distinção pelo modo pelo qual Kierkegaard tratou certos temas também abordados por outros filósofos, temos ainda hoje dificuldade em afirmar até que ponto o pensamento heideggeriano traz influências assumidas dos escritos de Kierkegaard. Não configura objetivo do presente trabalho argumentar acerca da influência do pensamento kierkegaardiano sobre a filosofia de Heidegger, mas de justificar que há pontos de estreitamento e distanciamento no modo pelo qual os dois pensadores compreendem o sentimento originado da angústia.

Para tanto, o texto se desenvolverá em três momentos principais. Inicialmente apresentaremos alguns pontos de aproximação do modo pelo qual Kierkegaard e Heidegger abordaram o tema da angústia, especialmente em suas relações com o homem, o nada e o medo. A seguir passaremos a tratar da ligação entre angústia e liberdade, objeto central do texto de Haufniensis. Em um momento final, buscaremos mostrar a tentativa heideggeriana de atribuir um sentido

WEBBER, Marcos André; WEBBER, Suelen da Silva. Entre Kierkegaard e Heidegger: uma reflexão sobre o sentido da angústia. Griot : Revista de Filosofia, Amargosa - BA, v.18, n.2, p.100-113, dezembro, 2018.

101 
ontológico à angústia, justificando que o fenômeno do angustiar-se não deveria ser compreendido apenas no contexto psicológico, uma vez que é a partir da angústia que abre-se ao Dasein o mundo enquanto mundo.

\section{A angústia como fenômeno humano}

A primeira e mais direta aproximação que podemos fazer entre as concepções de Kierkegaard e Heidegger deve-se à noção de que somente o homem faz a experiência da angústia. Em ambos os casos, a concepção de que somente o homem se angustia está em estreita ligação com o sentido do que significa ser humano para cada autor. Em $O$ conceito de angústia, sob o pseudônimo de Vigilius Haufniensis, Kierkegaard (2010a, p. 47) traz a definição de que o homem nada mais é do que espírito, sendo este entendido como uma síntese do psíquico e do corpóreo. Posteriormente, na obra $O$ desespero humano (Doença até a morte), sob o nome de Anti-Climacus, Kierkegaard acentua a concepção de que o homem é espírito, na seguinte passagem:

O homem é espírito. Mas o que é espírito? É o eu. E, o eu? O eu é uma relação, que não se estabelece com qualquer coisa de alheia a si, mas consigo própria. [...] $\mathrm{O}$ homem é uma síntese de infinito e de finito, de temporal e de eterno, de liberdade e de necessidade, é, em suma, uma síntese. Uma síntese é a relação de dois termos. Sob este ponto de vista, o eu não existe ainda. (KIERKEGAARD, 2010b, p. 25).

Ainda no texto de $O$ conceito de angústia, imediatamente após trazer a definição do homem enquanto espírito, Haufniensis questiona como este se relaciona consigo mesmo e com sua condição. Em sua resposta, o autor é enfático ao afirmar que "ele se relaciona como angústia" (KIER KEGAARD, 2010a, p. 47). Desse modo, na medida em que somente o homem é espírito (KIERKEGAARD, 2010a, p. 45), e este se relaciona consigo mesmo como angústia, Haufniensis está colocando em evidência uma relação que só diz respeito ao homem: a relação do espírito com a angústia.

Observe-se que o fato de que a angústia somente diz respeito ao homem é tratado por Haufniensis em diversos momentos de $O$ conceito de angústia, o que demonstra a relevância, no contexto da obra kierkegaardiana, de compreender a angústia como um sentimento marcadamente humano. No capítulo final da citada obra, no seu Caput V, Haufniensis é enfático ao afirmar:

Se um humano fosse um animal ou um anjo, não poderia angustiar-se. Dado que ele é uma síntese, pode angustiar-se, e quanto mais profundamente se angustia, tanto maior é o ser humano, mas não, contudo, no sentido em que os homens em geral o consideram, referindo a angústia a algo externo, como algo que é exterior ao homem, e sim no sentido de que ele mesmo produz a angústia. (KIERKEGAARD, 2010a, p. 163).

WEBBER, Marcos André; WEBBER, Suelen da Silva. Entre Kierkegaard e Heidegger: uma reflexão sobre o sentido da angústia. Griot : Revista de Filosofia, Amargosa - BA, v.18, n.2, p.100-113, dezembro, 2018. 
Ao menos dois pontos da citação acima merecem destaque na reflexão proposta neste trabalho: $a$ ) somente o ser humano pode angustiar-se; e $b$ ) o próprio homem é quem produz a angústia. Embora façamos a experiência da angústia como um poder exterior, ela emana de nós mesmos. Isso ocorre porque, no contexto da filosofia kierkegaardiana, a angústia pode ser considerada como constitutiva do self. Ela pertence a cada indivíduo enquanto indivíduo (KIERKEGAARD, 2010a, p. 57). $\mathrm{Na}$ medida em que a angústia reflete nossa relação com a possibilidade e o futuro, ela ilumina nossa natureza espiritual. Sob este aspecto, o pensamento de Kierkegaard pode contribuir para uma compreensão o sentimento da angústia como um fenômeno psicológico (MARINO, 1999, p. 319).

É o que ressalta Garaventa, ao destacar que "não existe nenhum indivíduo (incluindo Adão) que não tenha espírito ou não experimente a angústia; pelo contrário, neste elemento que assinala a liberdade do homem, a angústia é característica constante e natural no gênero humano" (GARAVENTA, 2011, p. 11). Ao mesmo tempo em que remete à insegurança que assinala a existência humana, a angústia pressupõe a experiência da infinitude, ou seja, a auto-experiência do Eu como espírito infinito, ainda que em conexão com a finitude, a temporalidade e a corporeidade.

Heidegger igualmente compreende a angústia como um sentimento unicamente humano, embora a análise empreendida em Ser e tempo não a tome como um fenômeno psicológico, mas em seu sentido ontológico. Há na filosofia de Heidegger uma clara preocupação em demonstrar que o homem possui um modo de ser distinto do modo de ser dos entes intramundanos. Ao sustentar esta distinção, Heidegger define o ser do Dasein como cuidado (Sorge), o qual possui uma estrutura triádica, composta pelos existenciais compreensão, sentimento de situação e decaída. Dentre os três existenciais, o sentimento de situação ganha relevância na medida em que a forma pela qual o mundo aparece ao Dasein está diretamente ligada ao seu estado afetivo. Daí porque a angústia, enquanto estado afetivo, não é tratada por Heidegger como um estado psicológico, mas como um modo de ser originário, a partir do qual o mundo aparece (HEIDEGGER, 2006, p. 136).

Fica fácil notar, desse modo, uma convergência entre as concepções de Kierkegaard e Heidegger no tocante ao caráter estritamente humano da angústia. Ambos autores compreendem que a angústia não deveria ser tomada como algo exterior ao homem: enquanto que Haufniensis afirma expressamente que o homem produz a angústia, Heidegger situa o sentimento de situação como parte da estrutura triádica que constitui o próprio ser do Dasein, a partir do qual o mundo lhe aparece. Uma distinção pode ser feita quanto ao caráter psicológico ou ontológico de cada análise, o que não afasta a característica da angústia de pertencer unicamente ao ser humano.

Além disso, em ambos os textos é possível destacar a notada preocupação dos autores em distinguir a angústia do medo. Para Haufniensis, o medo e outros conceitos semelhantes se referem a algo determinado, diferentemente da angústia, cujo objeto é justamente o nada. Aqui reside um dos principais motivos que levam Haufniensis a rejeitar a angústia no animal, visto que este não está determinado

WEBBER, Marcos André; WEBBER, Suelen da Silva. Entre Kierkegaard e Heidegger: uma reflexão sobre o sentido da angústia. Griot : Revista de Filosofia, Amargosa - BA, v.18, n.2, p.100-113, dezembro, 2018.

103 
como espírito: "por isso não se encontrará angústia no animal, justamente porque em sua naturalidade não está determinado como espírito" (KIERKEGAARD, 2010a, p. $45)$.

Marino (1999, p. 319) observa que, ao passo que pensadores como Kant e Hegel classificavam a angústia como um tipo de medo, Kierkegaard foi o primeiro a perceber que angústia e medo são conceitos distintos. Enquanto que o medo tem sempre um objeto determinado, o objeto da angústia permanece indeterminado. Podemos sem dúvida sentir medo se nos depararmos com um leão, uma vez que o objeto determinado "leão" coloca-se perante nós como algo ameaçador. Mas não sentimos angústia frente o leão, pois o objeto da angústia não é, de modo algum, algo que podemos determinar com precisão. Isso porque, na experiência da angústia, nos defrontamos com algo que pode ser possível, mas que nada é. Daí a afirmação de Haufniensis de que o objeto da angústia é um nada (KIER KEGAARD, 2010a, p. 83).

A questão que imediatamente se coloca é: o que devemos compreender com o termo "nada"? Para Haufniensis, "o nada ao redor do qual a angústia se forma é normalmente o futuro. Na medida em que o futuro está repleto de possibilidades, nossa relação com o futuro está repleta de angústia" (MARINO, 1999, p. 319). O nada, nesta perspectiva, está ligado às possibilidades que constituem um futuro que ainda não é. Isto se dá, na interpretação de Marino, pelo fato de que a angústia possui uma estranha relação com o pressentimento. Neste caso, importa lembrar que, sob nenhuma circunstância, pode o pressentimento - que na verdade é a própria angústia - determinar o pecado (MARINO, 1999, p. 319-320).

Neste mesmo sentido, explicita Garaventa que o pressentimento de que o homem deverá, cedo ou tarde, estabelecer a síntese que caracteriza o espírito, é o que nele produz a angústia. Na medida em que, para Kierkegaard, o homem não tem uma essência definida, e esta se faz através de suas escolhas, é justamente o "nada" que o indivíduo "é" no momento de estabelecer a síntese que produz angústia. A incerteza e a indefinição sobre as possibilidades que decorrem da liberdade colocam o indivíduo diante de algo que ainda não é, de possibilidades que ainda não são realidade, e que só cabe a ele decidir.

Heidegger mantém a distinção entre angústia e medo que Haufniensis chama a atenção, embora o sentido atribuído a tais conceitos pelo filósofo alemão não seja exatamente o mesmo. Segundo Heidegger, o medo provém sempre de um ente intramundano específico, como uma arma, um animal ou um gesto. Por isso diz-se que o ante-que do medo é sempre um ente intramundano (HEIDEGGER, 2006, p. 140). Já o ante-que da angústia não encontra no mundo um ente em particular, visto que ela se estabelece perante o próprio mundo enquanto tal (HEIDEGGER, 2006, p. 187). Na linguagem heideggeriana, podemos dizer que o medo sempre tem como um objeto um ente, mantendo-o na esfera ôntica (existentiell), enquanto que a angústia remete à esfera ontológica (existential), uma vez que diz respeito ao significado do mundo para o Dasein.

Ao mesmo tempo em que estabelece tal distinção, porém, Heidegger explica que a angústia é o que torna possível o medo. Conforme mencionado anteriormente, a descoberta do medo provém sempre de um ente intramundano, enquanto que o

WEBBER, Marcos André; WEBBER, Suelen da Silva. Entre Kierkegaard e Heidegger: uma reflexão sobre o sentido da angústia. Griot : Revista de Filosofia, Amargosa - BA, v.18, n.2, p.100-113, dezembro, 2018.

104 
ante-que da angústia "não é nada, não está em nenhuma parte"(HEIDEGGER, 2006, p. 186). É que, na concepção heideggeriana, a angústia possui um sentido ontológico, e por isso está ligada à significatividade do mundo. A experiência da angústia não consiste, pois, em um simples sentimento que emerge em determinadas situações, mas é o que abre ao Dasein o mundo enquanto mundo. Nas palavras de Heidegger,

o angustiar-se abre originária e diretamente o mundo enquanto mundo. Não se trata de que primeiramente se prescinda reflexivamente do ente intramundano e se pense somente no mundo, ante o qual surgiria então a angústia, mas que, pelo contrário, a angústia como modo de disposição afetiva, abre inicialmente o mundo enquanto mundo. No entanto, isso não significa que na angústia fique conceitualizada a mundaneidade do mundo. (HEIDEGGER, 2006, p. 187).

Desse modo, muito embora o contexto no qual Kierkegaard e Heidegger abordaram o tema da angústia sejam distintos, é possível perceber que em diversos momentos eles se aproximam. E apesar de tratarmos inicialmente da característica estritamente da angústia e das suas possíveis relações com o medo e com o nada, estes seguramente não são os únicos pontos de estreitamento entre as reflexões dos dois autores sobre o tema. Especialmente para Kierkegaard, a angústia está ligada diretamente à liberdade, e é sobre este assunto que passamos agora a tratar.

\section{Angústia e liberdade}

Como já mencionado anteriormente, $O$ conceito de angústia é um tratado sobre a liberdade humana, e é a partir da sua relação com a liberdade que o fenômeno da angústia passa a ser abordado. A liberdade, no entanto, não é compreendida por Haufniensis como uma realidade já dada, mas como uma possibilidade. Daí porque Haufniensis define a realidade da liberdade como "possibilidade antes da possibilidade" (KIERKEGAARD, 2010a, p. 45). Na medida em que a possibilidade consiste em uma variável indefinida, e dentre as possibilidades encontra-se a possibilidade da realidade da liberdade, segue que tal realidade somente existe enquanto possibilidade. Ao mesmo tempo em que o homem almeja a liberdade, sua realidade repousa em uma mera possibilidade, instaurando-se assim uma inquietude ambígua diante de algo que nada é. Esta inquietude ambígua é justamente a angústia (REBLIN, 2008, p. 109).

Na tarefa de existir, a experiência da angústia mostra ao homem a possibilidade da liberdade, de escolher e projetar-se a fim de construir-se, edificar-se (MARINO, 1999, p. 319). O homem passa assim a ser responsável por criar sua história, sem abolir a dependência ontológica que caracteriza a sua condição de criatura. Bem explica Farago que

o homem experimenta angústia diante da liberdade carregada com o peso esmagador que é sua tarefa autêntica, a de ser humano, a saber, sintetizar os termos heterogêneos do seu ser próprio, síntese que não pode jamais ser bem sucedida a ponto de se fazer desvanecer a angústia, porque, se a

WEBBER, Marcos André; WEBBER, Suelen da Silva. Entre Kierkegaard e Heidegger: uma reflexão sobre o sentido da angústia. Griot : Revista de Filosofia, Amargosa - BA, v.18, n.2, p.100-113, dezembro, 2018.

105 
angústia é angústia diante do salto da liberdade para a liberdade, a liberdade é a essência do espírito. (FARAGO, 2011, p. 95).

A noção de possibilidade, nesta perspectiva, ganha importância fundamental, pois o que é possível não equivale ao que é real. Ademais, a possibilidade da liberdade não se reduz a uma mera escolha, no sentido de que a podemos escolher algo, do mesmo modo que podemos escolher o seu oposto: "a possibilidade da liberdade não consiste em poder escolher entre o bem e o mal. Um tal disparate não prossegue nem das escrituras nem do pensamento. A possibilidade consiste em sercapaz-de" (KIERKEGAARD, 2010a, p. 53).

Em outras palavras, podemos afirmar que, para Haufniensis, a angústia revela o homem como uma potência capaz de realizar-se. Trata-se de um elemento indissociável da vida, que mostra que a realidade é precedida pela possibilidade da liberdade. Ao passo que na lógica a possibilidade passa facilmente para a realidade, na realidade efetiva ela precisa de uma determinação intermediária, caracterizada por Haufniensis como angústia. Por isso a afirmação que a liberdade "consiste em uma liberdade enredada, onde a liberdade não é livre em si mesma, mas tolhida, não pela necessidade, mas em si mesma" (KIERKEGAARD, 2010a, p. 53).

Quando, no Gênesis, Deus proíbe Adão de "comer dos frutos da árvore da ciência do bem e do mal", Adão não teria entendido tais palavras, uma vez que a distinção entre o bem e o mal só seguiria à fruição. Ocorre que, quando se admite que a proibição desperta um desejo, obtém-se um saber - justamente o saber acerca da liberdade. Segundo Haufniensis, "a proibição o angustia porque desperta nele a possibilidade da liberdade" (KIERKEGAARD, 2010a, p. 48). O que antes a inocência deixava passar desapercebido como o nada da angústia, agora se introduz como um novo nada: a angustiante possibilidade de ser-capaz-de.

Evidencia-se, na reflexão de Haufniensis, que há uma relação direta entre liberdade e temporalidade. Na medida em que a possibilidade se identifica com o porvir (KIERKEGAARD, 2010a, p. 99), a ligação da angústia com a liberdade se dá através da possibilidade que poderá se fazer realidade no futuro. Daí porque só nos angustiamos pelo passado se este estiver em uma relação de possibilidade para nós. Nas palavras de Haufniensis:

Se me angustio por um infortúnio passado, não é por aquilo que passou, mas sim por algo que pode vir as repetir-se, i. é, vir a ser futuro. Quando tenho angústia em razão de alguma culpa passada, é porque não a coloquei numa relação essencial comigo como algo passado, e de uma ou outra maneira enganadora impeço-a de se tornar passada. Se, com efeito, ela está realmente passada, não poderei sentir angústia em relação a ela, mas apenas arrependimento. Se não faço isso, ter-me-ei permitido entabular uma relação dialética com a culpa, porém com isso a própria culpa ficou uma possibilidade, e não algo passado. Se me angustio diante do castigo, isso só ocorre na medida que este é colocado numa relação dialética com a culpa (de outro modo, suporto o meu castigo), e então sinto angústia pelo possível e pelo porvir. (KIERKEGAARD, 2010a, p. 99).

WEBBER, Marcos André; WEBBER, Suelen da Silva. Entre Kierkegaard e Heidegger: uma reflexão sobre o sentido da angústia. Griot : Revista de Filosofia, Amargosa - BA, v.18, n.2, p.100-113, dezembro, 2018. 
Observe-se, na citação acima, que Haufniensis chama a atenção para uma relação entre angústia e culpa no contexto da temporalidade. Isso ocorre porque, na mesma proporção em que o indivíduo descobre a liberdade, avança sobre ele a angústia do pecado, no estado de possibilidade: "ele só teme a culpa, pois ela é a única coisa que pode roubar-lhe a liberdade" (KIERKEGAARD, 2010a, p. 116). Aqui o oposto da liberdade não é a necessidade, mas a culpa.

Há que se notar na reflexão de Haufniensis que, "se então a liberdade teme a culpa, o que ela teme não é reconhecer-se culpada caso o seja, mas o que ela teme é tornar-se culpada" (KIERKEGAARD, 2010a, p. 116). É por isso que, tão logo a culpa é posta, a liberdade retorna como arrependimento. Até aí, contudo, a relação da liberdade com a culpa permanece apenas enquanto possibilidade. Somente a liberdade por si mesma pode vir a saber se ela é liberdade ou se a culpa foi posta. Esta relação é justamente angústia, explicada por Haufniensis do seguinte modo:

\begin{abstract}
A relação da liberdade para com a culpa é angústia, porque a liberdade e a culpa ainda são possibilidade. Mas, à medida que a liberdade fixa seu olhar sobre si mesma com toda a sua paixão, e quer manter a culpa afastada de si, de modo que não reste dela nem uma penugem na liberdade, não consegue evitar cravar o olhar na culpa e essa fixação é a fixação ambígua da angústia, tal como até mesmo a renúncia no interior da possibilidade é um desejo. (KIERKEGAARD, 2010a, p. 116).
\end{abstract}

Para Haufniensis, é justamente neste sentido que para o indivíduo posterior há um "mais" na angústia comparada com a de Adão. A culpa mostra-se como uma representação mais concreta, que, na relação da possibilidade para com a liberdade, se torna cada vez mais possível. Isso ocorre porque a culpa tem a característica dialética de não se deixar transferir. A culpa, nesta perspectiva, tem sua origem no próprio indivíduo, e não a algo que lhe é externo. Quem se torna culpado, torna-se também culpado por aquilo que ocasionou a culpa, pois a culpa não tem como causa próxima algo de exterior. Nas palavras de Haufniensis, "aquele que cai na tentação, é culpado ele mesmo dessa tentação". (KIERKEGAARD, 2010a, p. 116-117)

Em Ser e tempo, diferentemente da obra de Haufniensis, a questão que assume papel central não é a possibilidade da liberdade, mas o sentido do ser. Certamente o tema da liberdade está presente, mas a preocupação principal na obra de 1927 estava voltada à elaboração da analítica existencial, a qual culminaria em uma ontologia fundamental, e se constituiria em uma etapa preparatória para a elaboração da questão do ser. Heidegger iria se ocupar mais diretamente da liberdade enquanto tema de reflexão nos textos do período imediatamente posterior a Ser e tempo, como exigência natural do direcionamento da própria investigação.

Há, contudo, no $\S 40$, uma importante passagem em que Heidegger associa a liberdade à angústia, nos seguintes termos:

A angústia revela no Dasein o estar voltado para o mais próprio poder-ser, ou seja, revela seu ser livre para a liberdade de escolher-se e tomar-se a si mesmo entre as mãos. A angústia leva o Dasein ante seu ser livre para... (propensio in...) a propriedade de seu ser enquanto a possibilidade que ele

WEBBER, Marcos André; WEBBER, Suelen da Silva. Entre Kierkegaard e Heidegger: uma reflexão sobre o sentido da angústia. Griot : Revista de Filosofia, Amargosa - BA, v.18, n.2, p.100-113, dezembro, 2018. 
é desde sempre. Mas este ser é, ao mesmo tempo, aquele ser a que o Dasein está entregue enquanto ser-no-mundo. (HEIDEGGER, 2006, p. 187).

Muito embora seja inegável a relação que Heidegger observa entre angústia e liberdade, na medida em que a angústia revela ao Dasein o seu ser livre para escolher-se e tomar-se de modo autêntico, é possível afirmar que, ao contrário de Haufniensis, o objetivo principal de Heidegger na análise da angústia não está em mostrar sua relação com a liberdade. Em que pese haver de fato uma ligação no texto heideggeriano entre o fenômeno da angústia e a liberdade, o projeto da ontologia fundamental - no qual insere-se também a angústia - objetivava estabelecer os alicerces existenciais para que a originariedade da questão do ser pudesse ser levantada de modo adequado.

Assim, ao passo que na primeira parte deste trabalho foi possível estabelecer uma aproximação direta no modo pelo qual os dois autores trataram do tema, aqui podemos indicar um momento em que Heidegger busca colocar o fenômeno da angústia em uma perspectiva até então inexplorada, para então interpretá-lo em sua relação com a questão do ser. Esta tentativa heideggeriana de analisar a angústia sob a perspectiva da ontologia fundamental é o que se passará a tratar na parte final do presente trabalho.

\section{Angústia em Heidegger}

Em Ser e tempo, Heidegger menciona Kierkegaard em três notas de rodapé. A primeira destas notas é encontrada no $\S 40$, a segunda no $\S 45$, e a terceira no $\S 68$. Na nota do $\S 40$, Heidegger faz referência a Kierkegaard ao tratar da disposição afetiva da angústia no âmbito da analítica existencial. Tal referência aparece justamente no momento em que Heidegger busca caracterizar a angústia como um fenômeno ontológico, relacionado ao ser do Dasein. A menção a Kierkegaard aparece nos seguintes termos: "S. Kierkegaard é quem mais profundamente penetrou na análise do fenômeno da angústia, e, certamente, uma vez mais, dentro do contexto teológico de uma exposição 'psicológica' do problema do pecado original. Cf. O conceito de angústia, 1844". (HEIDEGGER, 2006, p. 190)

$\mathrm{Na}$ análise feita por Heidegger, a omissão de uma analítica existencial e o desconhecimento do fenômeno da disposição afetiva impediram que a angústia tivesse sido anteriormente interpretada em sua constituição fundamental e função ontológico-existencial. Assim, ao referir-se ao pensamento de Kierkegaard na nota de rodapé do $\S 40$, Heidegger revela sua interpretação do modo pelo qual o tema da angústia foi tratado ao longo da história da filosofia, motivo pelo qual o filósofo dinamarquês está acompanhado por Santo Agostinho e Lutero na mesma nota. Heidegger demonstra ter conhecimento da forma pela qual os três pensadores citados trataram dos temas do medo e da angústia, tanto ôntica como ontologicamente, no horizonte da teologia cristã. Dentre eles, Kierkegaard recebe um destaque, por ser, nas palavras do filósofo alemão, "quem mais profundamente penetrou na análise do fenômeno da angústia", embora sua análise mantenha-se no contexto teológico de uma exposição "psicológica" do problema do pecado original.

WEBBER, Marcos André; WEBBER, Suelen da Silva. Entre Kierkegaard e Heidegger: uma reflexão sobre o sentido da angústia. Griot : Revista de Filosofia, Amargosa - BA, v.18, n.2, p.100-113, dezembro, 2018.

108 
Nessa medida, Heidegger atribui um destaque à abordagem que Kierkegaard faz do tema da angústia, dada a profundidade da análise por ele realizada na obra $O$ conceito de angústia. Por outro lado, não podemos ignorar que, junto ao elogio constante da citada nota de rodapé, o autor de Ser e tempo afirma que o pensador dinamarquês não esgotou o assunto, acusando a análise de Kierkegaard de ter permanecido no âmbito ôntico. Heidegger, justamente em razão do projeto da ontologia fundamental, busca atribuir à angústia uma dimensão ontológica, o que configura talvez a principal distinção na concepção da angústia entre dois pensadores.

A distinção entre o ôntico e o ontológico - que Heidegger viria a denominar diferença ontológica - é fundamental na filosofia heideggeriana, visto que ela se refere à distinção entre ser e ente. Enquanto que o ôntico diz respeito ao ente, o ontológico tem como objeto o ser do ente, cuja compreensão é primazia do Dasein. Ôntico e ontológico, porém, não devem ser compreendidos como instâncias isoladas. Há uma relação entre elas que diferencia o Dasein dos demais entes, visto que só ele possui a condição de possibilidade ôntico-ontológica:

\begin{abstract}
A escolha entre "ser si mesmo e de não ser" implica uma determinação. Essa se divide em ôntica, que define o Dasein como ente; e uma ontológica, que explicita a base de compreensão do ser. Ambas se relacionam: a ôntica tem como fundo uma dimensão ontológica, porque a compreensão é determinante no primado ôntico do ontológico. Essa determinação diferencia o Dasein dos demais entes, pois, em seu próprio ser, abre-se a possibilidade de compreensão dos demais entes. A abertura conduz o Dasein ao seu ser mais próprio: a tarefa de existir. (VEIGA, 2012, p. 35).
\end{abstract}

Ao permanecer na esfera ôntica em sua análise da angústia, não foi possível a Kierkegaard perceber o que se coloca "antes", e como pré-condição para o contato do homem com os entes, a saber, a compreensão do ser. E é exatamente nesta instância prévia, à qual Heidegger denomina ontológica, que se situa a reflexão heideggeriana sobre a angústia. Sob este aspecto, o filósofo alemão busca dar à angústia uma nova dimensão, tomando-a como constitutiva do ser do Dasein. A angústia, mostra-se, nesta perspectiva, uma disposição afetiva que possui relação com a compreensão que o Dasein tem do mundo e de si mesmo. Na experiência da angústia, o mundo perde o sentido para o Dasein, o qual é colocado ante o seu ser-no-mundo, livre para escolher-se a si mesmo.

Na interpretação ontológica do fenômeno da angústia, não apenas um angustiar-se ante..., mas também um angustiar-se por..., que abre originariamente o mundo enquanto mundo. Isso porque aquilo pelo que a angústia se angustia é o serno-mundo enquanto tal, explicado por Mulhall na seguinte passagem:

Para Heidegger, o que nos oprime não é qualquer totalidade específica de objetos prontos-à-mão mas, antes, a possibilidade de tal totalidade: nós estamos oprimidos pelo mundo enquanto tal - ou, mais precisamente, pelo Ser-no-mundo. A angústia confronta o Dasein com o conhecimento de que está lançado no mundo - sempre já lançado em situações de escolha e de

WEBBER, Marcos André; WEBBER, Suelen da Silva. Entre Kierkegaard e Heidegger: uma reflexão sobre o sentido da angústia. Griot : Revista de Filosofia, Amargosa - BA, v.18, n.2, p.100-113, dezembro, 2018. 
ação que importam a ele mas que ele não escolheu nem determinou completamente. Ela confronta o Dasein com o fato determinante e absolutamente contingente da sua própria existência mundana. (MULHALL, 2005, p. 111).

Nestes termos, destaca-se que a angústia leva o Dasein a confrontar-se a si mesmo e a encarar o fato de que seu ser consiste em um poder-ser, cuja existência envolve a projeção de si mesmo em possibilidades de ser. O Dasein passa então a perceber que não há no mundo um fundamento seguro em que possa se apoiar para guiar suas decisões. Pelo contrário, a angústia mostra um Dasein sozinho no mundo, para quem o mundo não tem sentido, e que por isso precisa encontrar a si próprio, sem poder, para tanto, recorrer à padronização do Das Man. Afetado pela angústia, o Dasein é colocado ante si mesmo em sua singularidade como ser-no-mundo. Conforme esclarece Heidegger,
a angústia singulariza e abre o Dasein como um solus ipse. Mas este "solipsismo", longe de instalar a uma coisa-sujeito isolada no inócuo vazio de um ser-aí carente de mundo, leva precisamente o Dasein, em um sentido extremo, ante seu mundo como mundo, e, consequentemente, ante si mesmo como ser-no-mundo. (HEIDEGGER, 2006, p. 188).

A angústia passa assim a ser compreendida como o sentimento de situação que possibilita ao Dasein perceber-se distinto do Das Man, e que precisa encontrar a si mesmo. Enquanto que, perdido no Das Man, o Dasein não é ninguém, a angústia aponta para o fato de que o Dasein incorre em uma compreensão equivocada de si mesmo. Assim, permanecer no modo de ser inautêntico do Das Man significa fugir de si mesmo, da finitude e da responsabilidade pelo próprio ser. É o que explica Capobianco, ao sustentar que,

na inautenticidade, o Dasein encontra múltiplas formas de fugir da angústia e da verdade que ela revela; já na autenticidade, o Dasein coloca um fim na fuga e aceita de forma resoluta sua finitude e a disposição da angústia que a acompanha. Assim, como ele desenvolveu em Ser e tempo, a disposição da angústia é mais fundamentalmente constitutiva do Dasein que qualquer outra disposição, e confrontar e assumir de forma resoluta a angústia é definitivamente uma característica da existência autêntica. (CAPOBIANCO, 2011, p. 70).

O caráter ontológico que Heidegger atribui à angústia reside justamente na compreensão equivocada do mundo que ela provoca no Dasein. "Na angústia, o Dasein experiencia o mundo como um instrumento que falhou em realizar o seu trabalho" (DREYFUS, 1991, p. 179). A familiaridade que o Dasein mantém com o mundo, decorrente do modo de ser do Das Man, é derrubada pela angústia: "a angústia traz o Dasein de volta da sua absorção 'no mundo"' (HEIDEGGER, 2006, p. 189). Abre-se, assim, a possibilidade do Dasein compreender-se como distinto do Das Man, e então poder conduzir a sua própria vida a partir de uma compreensão adequada de si mesmo enquanto ser-no-mundo. $O$ processo de singularização mostra

WEBBER, Marcos André; WEBBER, Suelen da Silva. Entre Kierkegaard e Heidegger: uma reflexão sobre o sentido da angústia. Griot : Revista de Filosofia, Amargosa - BA, v.18, n.2, p.100-113, dezembro, 2018. 
a autenticidade e a inautenticidade como possibilidades, mas que só poderão se concretizar a partir da experiência da angústia e da recuperação de si mesmo frente ao Das Man. Nas palavras de Heidegger,

\begin{abstract}
somente na angústia se dá a possibilidade de uma abertura privilegiada porque ela singulariza. Esta singularização recupera o Dasein arrancandoo de sua decaída, e revela a autenticidade e a inautenticidade como possibilidades do seu ser. Estas possibilidades fundamentais do Dasein, que é cada vez meu, se mostra na angústia tais como são em si mesmas, não desfiguradas pelo ente intramundano a que o Dasein imediata e regularmente se prende. (HEIDEGGER, 2006, p. 190-191).
\end{abstract}

Desse modo, ao atribuir um sentido ontológico para a angústia e situá-la no projeto da ontologia fundamental, Heidegger almeja mostrar algo sobre o fenômeno do angustiar-se que não foi observado pela tradição. Mesmo reconhecendo o esforço de Kierkegaard em analisar e descrever a relação da angústia com a existência, Heidegger busca dar um passo adiante na elucidação do significado da angústia e nossa existência. Assim, muito mais do que um sentimento ou um fenômeno psicológico, para Heidegger a angústia está diretamente ligada ao modo como compreendemos não apenas o mundo, mas também a nós mesmos.

\title{
Considerações Finais
}

Apontar aproximações e distanciamentos entre os modos pelos quais Kierkegaard e Heidegger compreendem a angústia exige uma tarefa prévia de explicitar os contextos nos quais tal conceito está inserido no âmbito dos textos produzidos pelos dois pensadores. Na medida em que compreendermos a função que a angústia desempenha para cada autor, tona-se então possível não apenas colocar em evidência alguns pontos de similaridade e diferenças entre as relações que o sentimento da angústia pode vir a manter com a existência para cada pensador, mas compreender a tentativa heideggeriana de explorar o sentido da angústia para além dos limites do empreendimento do pensador dinamarquês.

Sob este aspecto, merece atenção o fato de que $O$ conceito de angústia é um tratado sobre a liberdade humana, que compreende a existência humana como uma luta constante na busca da realização. A análise da angústia, no texto de Haufniensis, se desenvolve em conexão com a possibilidade da liberdade, juntamente com conceitos cristãos como pecado, culpa e fé. Ser e tempo, por outro lado, é um texto preparatório para o enfrentamento da questão do ser, justificando a abordagem da angústia em sua conexão com o modo pelo qual é possível ao Dasein algo como uma pré-compreensão do ser. A angústia, nesta perspectiva, passa a ser compreendida em sua relação com existenciais, que possibilitam ao Dasein assumir modos de ser autênticos ou inautênticos.

As noções de que a angústia constitui uma experiência que diz respeito unicamente ao homem, que ela é distinta do medo, e que há uma relação entre a angústia e o nada podem ser apontados como aproximações entre os modos pelos

WEBBER, Marcos André; WEBBER, Suelen da Silva. Entre Kierkegaard e Heidegger: uma reflexão sobre o sentido da angústia. Griot : Revista de Filosofia, Amargosa - BA, v.18, n.2, p.100-113, dezembro, 2018. 
quais os dois autores abordaram o tema. E embora possamos ainda afirmar que em ambas as concepções a angústia possui relação com a liberdade, é possível notar algumas distinções fundamentais. Enquanto que para Kierkegaard a angústia torna possível a experiência da liberdade, Heidegger busca mostrar que a experiência da angústia possui um sentido ontológico, e não apenas psicológico. Pois é justamente neste ponto que reside talvez a principal diferença na reflexão dos dois pensadores.

Heidegger sem dúvida reconhece o esforço de Kierkegaard em sua análise sobre o tema da angústia, conforme se observa na nota de rodapé do $§ 40$ de Ser e tempo, mas ao mesmo tempo busca dar um passo adiante na descrição da relação do fenômeno da angústia com a existência. Enquanto que a análise de Kierkegaard teria permanecido na esfera ôntica, Heidegger almeja evidenciar que a angústia não deveria ser compreendida como um fenômeno psicológico. Uma vez que a angústia revela no Dasein o estar voltado para o mais próprio poder-ser, e com isso o ser livre para a liberdade de escolher a si mesmo, pode o Dasein perceber-se distinto do Das Man, e assim assumir de modo próprio a sua tarefa de existir.

WEBBER, Marcos André; WEBBER, Suelen da Silva. Entre Kierkegaard e Heidegger: uma reflexão sobre o sentido da angústia. Griot : Revista de Filosofia, Amargosa - BA, v.18, n.2, p.100-113, dezembro, 2018. 


\section{Referências}

CAPOBIANCO, Richard. Engaging Heidegger. Toronto: University of Toronto Press, 2011.

CAPUTO, John D. How to read Kierkegaard. New York: W. W. Norton \& Company, Inc., 2008.

DREYFUS, Hubert L. Being-in-the-world: a commentary on Heidegger's being and time, division I. Cambridge, Massachusetts: The MIT Press, 1991.

FARAGO, France. Compreender Kierkegaard. Trad. de Ephraim F. Alves. 3. ed. Petrópolis, RJ: Vozes, 2011.

GARAVENTA, Roberto. Søren Kierkegaard: uma fenomenologia da angústia. Sacrilegens, Juiz de Fora, v. 8, n. 1, p. 05-19, 2011.

HEIDEGGER, Martin. Sein und Zeit. 19. ed. Tübingen: Max Niemeyer Verlag, 2006.

KIERKEGAARD, Søren A. O conceito de angústia: uma simples reflexão psicológicodemonstrativo direcionada ao problema dogmático do pecado hereditário. Trad. Álvaro Luiz Montenegro Valls. 2. ed. Petrópolis, RJ: Vozes; São Paulo, SP: Editora Universitária São Francisco, 2010a.

Unesp, 2010b.

O desespero humano. Trad. Adolfo Casais Monteiro. São Paulo: Editora

MARINO, Gordon D. Anxiety in the concept of anxiety. IN: The Cambridge Companion to Kierkegaard. Cambridge: Cambridge University Press, 1999.

MULHALL, Stephen. Routledge philosophy guidebook to Heidegger and being and time. 2. ed. London: Routledge, 2005.

REBLIN, Iuri Andréas. A angústia kierkegaardiana. Protestantismo em Revista, v. 16, p. 105-127, 2008.

THONHAUSER, Gerhard. Martin Heidegger reads Søren Kierkegaard - or what did he actually read? Kierkegaard Studies Yearbook, 2016, p. 281-304.

VEIGA, Itamar S. Cotidiano e queda: uma análise a partir do $\S 38$ de Ser e tempo. Porto Alegre: Clarinete, 2012.

\section{Contribuição dos autores}

Suelen da Silva Webber contribui com as pesquisas em torno da gênese da filosofia heideggeriana e seu diálogo com outros filósofos. Marcos André Webber contribuiu com as pesquisas sobre as implicações da analítica existencial em relação ao tema proposto. Ambos autores aprovaram a versão final do artigo.

Autor(a) para correspondência: Marcos André Webber, Universidade do Vale do Rio dos Sinos, Av. Unisinos, 950 - Cristo Rei, CEP 93020-190, São Leopoldo-RS, Brasil.

marcoswebber@wcacontabilidade.com.br

WEBBER, Marcos André; WEBBER, Suelen da Silva. Entre Kierkegaard e Heidegger: uma reflexão sobre o sentido da angústia. Griot : Revista de Filosofia, Amargosa - BA, v.18, n.2, p.100-113, dezembro, 2018. 